\title{
Factors associated with stress when caring for a child with a short stature
}

\author{
Sara Casaña-Granell ${ }^{1}$ (D) $\cdot$ Laura Lacomba-Trejo ${ }^{1}$ (D) - Inmaculada Montoya-Castilla ${ }^{1}$ (D) $\cdot$ Marian Pérez-Marín ${ }^{1}$
}

Accepted: 22 December 2020

(C) The Author(s), under exclusive licence to Springer Science+Business Media, LLC part of Springer Nature 2021

\begin{abstract}
Short stature (SS) is one of the main diagnoses in Pediatric Endocrinology. SS can have a negative impact on family dynamics, causing stress and psychopathology. Poor adaptation by the family caregiver negatively affects the pediatric patient. Our objective was therefore to study the adjustment of the main family caregivers of pediatric patients with SS, analyzing the factors influencing it. One hundred and ten primary family caregivers of pediatric SS patients from hospitals in Valencia, Spain, participated. Parental stress (Pediatric Inventory for Parents), anxious and depressive symptoms (Hospital Anxiety and Depression Scale), family functioning (Family Cohesion and Adaptation Scale), and adult attachment (Adult Attachment Questionnaire) were evaluated. Fuzzy set qualitative comparative analysis (fsQCA) was performed. The caregiver's age, anxiety, and attachment variables are significant when predicting the main family caregiver's adaptation to the stress caused by the diagnosis. These results will help improve adaptation to the diagnosis, since healthcare personnel will be able to establish that caregivers and/or families present a greater risk of mismatch more quickly and apply the necessary intervention.
\end{abstract}

Keywords Short stature $\cdot$ Adolescent development $\cdot$ Caregiver $\cdot$ Stress $\cdot$ Anxiety $\cdot$ Depression

\section{Introduction}

Adolescence is a stressful period of development, and one of the most important and problematic times of change in family life (Papalia, Wendkos, \& Duskin, 2013). Despite their maturity, stressful events can cause psychological, physiological and emotional problems for adults, given the major responsibilities they will have to assume (Orkaizagirre-Gómara, Sánchez, Ortiz, \& Ortiz, 2020).

Short Stature (SS) is one of the most frequent problems in pediatric endocrinology units (Pombo, Castro-Feijóo, \& Cabanas, 2011). SS is considered to occur when a child's

Marian Pérez-Marín

marian.perez@uv.es

Laura Lacomba-Trejo

laura.lacomba@uv.es

Inmaculada Montoya-Castilla

inmaculada.montoya@uv.es

1 Department of Personality, Assessment and Psychological Treatments, Faculty of Psychology, University of Valencia, Av. Blasco Ibáñez, 21, 46010 Valencia, Spain height is below $-2 \mathrm{SD}$ for their age and sex compared to the reference population, or in other words, below the third percentile. The greater the deviation of the height from the population's mean and/or the family's genetic growth potential, the higher the probability of an underlying pathology (Ying-Ju et al., 2020). It is more common among boys than girls (Wu et al., 2020), and 13-year-old patients are those that most frequently consult physicians (Aizpurua et al., 2020). Although diagnosis is complicated due to the diversity of definitions, between $24.9 \%$ and $26.2 \%$ of pediatric patients are diagnosed with SS (Zayed et al., 2016).

After the diagnosis of SS, pediatric patients usually visit the doctor regularly for a clinical examination of their height, weight, sexual characteristics and maturity, as well as an auscultation, a blood test and an x-ray of the hand to see the bone growth. Depending on various medical criteria, adolescents may receive growth hormone therapy. Regardless of the etiology, one of the goals of therapy for GH deficiency in a child with SS is to normalize the child's height during childhood, which as mentioned above is abnormally short compared to other individuals, and to improve the adult height and prevent the negative psychological consequences of being short. For children who meet the criteria for growth hormone, treatment consists of a daily injection of growth hormone for years. 
Although there are usually no side-effects, some of them can be serious (Pombo et al., 2011). However, in Spain, the majority of patients who come consult physicians due to SS belong to the idiopathic category, and implementation of the treatment in these cases is still being studied (González \& González, 2011). However, those adolescents who are treated with $\mathrm{GnHr}$ often present better emotional health than those who do not receive it. Similarly, primary caregivers who have children who receive medical treatment tend to show better results (Silva et al., 2018).

Adaptive, emotional and organizational changes in the family are inevitable when a child is diagnosed and requires continuous or chronic follow-up (Casaña-Granell et al., 2018). An SS diagnosis can have a severe impact on the physical and emotional health of both the pediatric patient and the primary caregiver, given the important role they play in care (Quitmann et al., 2019; Quitmann, Bullinger, Sommer, Rohenkohl, \& Da Silva, 2016). It is common for pediatric caregivers to show stress and emotional symptoms such as anxiety and depression (Casaña-Granell et al., 2018; ValeroMoreno et al., 2018).

Psychological stress is one of the most important factors in assessing the level of adjustment and adaptation of parents to their child's diagnosis (Johnson, 2013). Primary caregivers develop stress-related symptoms upon their children's diagnosis (Casaña-Granell et al., 2018; Valero-Moreno et al., 2018). This emotional distress occurs more often than in parents with children who are not chronically ill (Wang, Bai, Lou, Pang, \& Tang, 2020) and the stress levels of parents of pediatric SS patients are similar to and comparable with those of other parents coping with pathologies requiring more invasive care (Casaña-Granell et al., 2018; Valero-Moreno et al., 2018), regardless of the age of the primary caregiver (Del Rincón, Remor, \& Arranz, 2007; Streisand, Braniecki, Tercyak, \& Kazak, 2001;Vrijmoet-Wiersma, Ottenkamp, van Roozendaal, Grootenhuis, \& Koopman, 2009).

As well as stress, anxiety and depression have been found to be two very important variables in predicting and explaining the burden felt by the primary caregiver of adolescents with SS (Casaña-Granell et al., 2018). Primary family caregivers of children requiring continuous or chronic medical follow-up have high levels of anxiety and depression (CasañaGranell et al., 2018; Sicouri et al., 2017; Valero-Moreno et al., 2018). The presence of stress or emotional symptoms in the primary caregiver is associated with increased discomfort among their adolescent children with chronic illness, worsening the course and outcome of the illness (Silva et al., 2018).

When a stressful situation such as a chronic illness occurs in a child, the attachment system is activated, and as such the theory of adult attachment can help us understand the experience of caregivers (Brennan \& Shaver, 1995; Xiaoyun \& Fenglan, 2020). According to the theory of adult attachment, depending on the type of attachment a person develops, he or she will be able to cope with stressful situations more or less successfully (Berenguer-Pérez, Barreto-Martín, \& PérezMarín, 2018). Accordingly, adults with secure models tend to be more skilled at regulating and expressing their emotions and resolving difficulties (Mikulincer \& Shaver, 2018), and also recover more quickly in the face of adversity (Mikulincer \& Shaver, 2012). On the other hand, adults with insecure attachment characteristics tend to have poorer emotional regulation in the face of adversity and more negative personal and worldly patterns, leading to more negative emotionality and multiple psychological problems (Balola, Cláudio, \& do Rosário Ramos, 2019; Kimelman, 2019; Mikulincer \& Shaver, 2018; Morán \& Martínez, 2019). Secure attachment is considered a protective factor in the emotional well-being of carers (Nicholls et al., 2014) and insecure attachment is considered a risk factor for all these reasons (Xiaoyun \& Fenglan, 2020).

On the other hand, attachment can influence the way people relate to each other in the family. Those with insecure attachments tend to present less family cohesion and adaptation (Alavi, Latif, Ninggal, Mustaffa, \& Amini, 2020). According to de Olson's circumflex model (2000), cohesion is the emotional bond between people in the family. Adaptability, on the other hand, is the capacity of the family system to adapt its power structures, rules and roles when facing a stressful situation, such as the suffering of a child. In addition, if the family has a balanced cohesion, the conflicts that arise can benefit the family and improve the relations within it (Monaghan, Horn, Alvarez, Cogen, \& Streisand, 2012). However, if it occurs in a context of unbalanced cohesion, the conflict becomes as hostile, and may lead to a failure by the adolescent to interact with their parents (Cano et al., 2020), worsening the course and outcome of the child's illness (Monaghan et al., 2012). In addition, adequate family cohesion and adaptability reduces the appearance of psychopathology in the system (Alavi et al., 2020), thereby improving the physical and emotional adaptation of the primary caregiver and the adolescent with a chronic illness (Lei \& Kantor, 2020; Tsibidaki, 2020; Valero-Moreno et al., 2018).

Due to all of the reasons above, the aim of this study will therefore be to assess the adaptation of primary family caregivers to the SS diagnosis of a pediatric patient (as related to the stress of care) and to determine the personal and family factors which influence and can predict this adaptation process. Models based on comparative qualitative analysis (QCA) will be used to that end, given that they have been shown to be more explanatory than linear models, in addition to providing indicators of the fit and adequacy of the model (Giménez-Espert, Valero-Moreno, \& Prado-Gascó, 2019). QCA allows different paths to follow to be studied (combining a particular interaction between study variables) in order to optimize the prediction of the dependent variables analyzed (Ragin, 2008). 


\section{Methods}

\section{Participants, Procedure and Data Analysis}

A total of 101 primary caregivers participated, of whom $90.1 \%$ were women $(n=91)$, and $9.9 \%$ were men $(n=10)$. The most common relationship was "mother" $(86.1 \%$; $n=88)$, followed by "father" $(9.9 \% ; \mathrm{n}=10)$, "sister" $(2 \%$; $\mathrm{n}=1)$ and "foster mother" $(2 \% ; \mathrm{n}=1)$. The mean age was 44.74 years $(\mathrm{SD}=4.28)$, with a minimum of 33 and a maximum of $54.51 .20 \%$ of the participants' children had been treated with $\mathrm{GnRh}$ for 5 years $(\mathrm{M}=4.92$; $\mathrm{SD}=3.87)$. As inclusion criteria, we used family members who were responsible for the adolescent diagnosed with SS (i.e. whose height was below $-2 \mathrm{SD}$ compared to age and sex in comparison to the reference population, or below the 3rd percentile), and all of them were assigned to the pediatric endocrinology unit at one of the three main hospitals of the Valencian Community in Spain. As an exclusion criterion, caregivers of patients with SS were excluded who despite meeting the above criteria, presented a diagnosis of an additional physical or psychological pathology or cognitive difficulties prior to the evaluation of this study.

After their appointment at the Pediatric Endocrinology clinic, and the primary and adolescent caregivers had signed the informed consent form, the patients were evaluated in a single assessment pass between April 2015 and October 2017, with the supervision of both a psychologist trained in evaluation and an expert in the hospital setting. This research was approved by the Ethics Committee of the University of Valencia Review Board (IRB) (Date. 02-03-2015/No. H141815452530).

Then, the IBM SPSS Statistics 26 (IBM Corporation) software was used to perform the descriptive analyses, and, fsQCA 2.5 (Claude \& Christopher, 2014) was used to perform the fuzzy set qualitative comparative analysis (fsQCA) models. The QCA evaluates the combination of causal and independent variables, and how these sets of variables predict the dependent variable, depending on the different combinations. The dimensions "PIP Total Frequency or stress relative to the frequency of situations derived from care" and "PIP Total Difficulty or stress relative to the effort involved in situations derived from care" from the PIP were used in this study. Meanwhile, the independent variables (chosen from the dimensions of those instruments, taking the scientific literature into account) were age, anxiety, depression, family cohesion, and the scales "low self-esteem, need for approval and fear of rejection" and "emotional self-sufficiency and discomfort with intimacy" from the AAQ in the PIP Total Frequency dimension; and age, anxiety, depression, family cohesion, and the scales "low self-esteem, need for approval and fear of rejection", "hostile resolution of conflicts, resentment and possessiveness" and "expression of emotions, solution of interpersonal problems and comfort with relationships" from the AAQ in the PIP Total Difficulty dimension.

First, descriptive analyses of the participants were estimated; calibration values for fsQCA were then calculated, and a fuzzy-set qualitative comparative analysis (fsQCA) was subsequently performed. The raw data from the participants' responses were transformed into fuzzy-set responses to perform the fuzzy-set qualitative comparative analysis. The cut-off points or percentiles (the 10th, 50th and 90th percentiles, like the three thresholds used by Woodside, 2013) offered by the authors of the questionnaires used were taken into account. First, the missing data were eliminated and all the variables (or constructs) were recalculated: these were Anxiety (Absence $=$ $0)($ Probable Case $=0.49)($ Presence $=1)$; Depression $($ Absence $=0)($ Probable Case $=0.49)($ Presence $=1)$; "Low self-esteem" in the AAQ $($ Low $=0)($ Medium $=0.49)($ High $=$ 1); "Expression of emotions" in the AAQ (Low $=0$ ) (Medium = 0.49) $($ High = 1); "Hostile Resolution" in the AAQ (Low = $0)($ Medium $=0.49)($ High $=1)$; "Emotional self-sufficiency" in the AAQ $($ Low $=0)($ Medium $=0.49)($ High $=1)$; Family Cohesion (Dysfunctional Family $=0$ ) (Functional Family $=$ 1). The age values of the primary family caregiver were recalibrated as follows: 10\% (low agreement or fully outside the set), $50 \%$ (intermediate level of agreement, neither inside nor outside the set), and $90 \%$ (high agreement or fully in the set).

The need and sufficiency analyses were subsequently carried out to assess the effect of the variables on the dimensions of the PIP. In the sufficiency analyses, the membership scores of the fuzzy set are first transformed into a truth table, which assesses all combinations that are possible causal conditions and the outcome of each combination. Second, the QCA analysis provides three possible solutions: the complex, the parsimonious and the intermediate solution, with the intermediate solution recommended (Ragin, 2008). This will therefore be the one presented from now on.

\section{Instruments}

Based on the previous literature, the following validated instruments were selected for use in Spanish samples within the age range of the present study.

The Pediatric Inventory for Parents (PIP) (Streisand, 2001; Casaña-Granell et al., 2018) The PIP is a questionnaire that assesses the stress levels of the primary caregivers of children with a chronic illness. The shortened version of the PIP (Casaña-Granell et al., 2018), has a Likert scale format, ranging from 1 to 5 (never/not at all) to 5 ("very often/extremely). It consists of 12 items, which give rise to four subscales for frequency of care and effort or difficulty of care. The items can be divided into four subcategories: communication (e.g. "Waiting for my child's medical test results"), medical care 
("Helping my child with medical procedures"), role function (e.g. "Having little time to attend to my own needs") and emotional functioning (e.g. "Worrying about the long-term consequences of the disease"). In addition, two total scores can be obtained (one for frequency and one for effort). Higher scores indicate greater stress in care. It has presented adequate psychometric properties ( $\alpha=0.78$ to 0.98 ) (CasañaGranell et al., 2018). In the present study it obtained adequate values of internal consistency $\left(\alpha_{\text {frequency }}=0.81\right.$ and $\alpha_{\text {effort }}=$ $0.84)$.

The Hospital Anxiety and Depression Scale (HADS) (Zigmond \& Snaith, 1983) This scale evaluates anxietydepressive symptoms in hospital patients by eliminating somatic symptoms. It consists of 14 items: 7 for anxiety (e.g. "I feel tense or "wound up"') and 7 for depression (i.e. "I feel as if I am slowed down"), and a total score for emotional distress can be obtained. It has a Likert scale format (0 to 3 ) and has shown adequate internal consistency (0.68 to 0.93$)$ in other studies (Quintana et al., 2003; Valero-Moreno et al., 2019) and in this $\left(\alpha_{\text {anxiety }}=0.75 ; \alpha_{\text {depression }}=0.66 ; \alpha_{\text {emotional }}\right.$ distress $=0.89$ ).

The Family Adaptability and Cohesion Evaluation Scales III (CAF, FACES-III) (Olson, Portner, \& Lavee, 1985) This scale was created in order to construct a measuring instrument to evaluate the variables that form the dynamics of a family, based on the circumplex model of Olson, Russell, and Sprenkle (1983). This model initially consisted of two dimensions: a) "cohesion", the emotional bond between the members of a family (e.g. "We feel more united among ourselves than with people who are not part of the family"), and b) the family's "adaptability/flexibility", i.e. the family's ability to change and adapt to changes (e.g. "We exchange responsibilities (tasks and duties) of the house"). The questionnaire consists of 20 items on a Likert scale with five alternatives, ranging from "Almost never" to "Almost always". Adequate psychometric properties have been shown in previous studies (Pampliega, Castillo, Sanz, \& Galíndez, 2006). The internal consistency values were. 0.63 for "Cohesion", and 0.27 for "Adaptation".

The Adult Attachment Questionnaire (AAQ) (Melero \& Cantero, 2008) When constructing this instrument, we used all the theoretical constructs that characterize attachment styles. It is composed of 40 items, with a Likert scale of 6 points ( 1 completely disagree; 6 completely agree). These items are grouped into 4 scales: low self-esteem, the need for approval and fear of rejection (e.g. "Often, despite being with people who are important to me, I feel lonely and unloved"); hostile resolution of conflicts, resentment and possessiveness (e.g. "I do not admit discussions if I think I am right"); expression of feelings and comfort with relationships

(e.g. "I have the ability to express my feelings and emotions"); emotional self-sufficiency and discomfort with intimacy (e.g. "I never seriously commit to my relationships"). The various scales have favorable psychometric properties, with reliability indexes ranging from 0.77 to 0.86 (Melero \& Cantero, 2008). The internal consistency values in this study were adequate $\left(\alpha_{\text {low esteem }}=0.82 ; \alpha_{\text {hostile }}=0.72 ; \alpha_{\text {expression }}=0.63 ; \alpha_{\text {self- }}\right.$ sufficiency $=0.53)$.

\section{Results}

The results of the Comparative Qualitative Analysis of Fuzzy Sets (fsQCA) are presented below. First, the main descriptors and calibration values for the variables studied are presented (Table 1).

\section{Requirement Analysis}

Considering the results obtained (Table 2), we did not observe that any condition was necessary for the occurrence or otherwise of the PIP (Total Frequency and Total Difficulty) dimensions, because the consistency was $<0.90$ in all cases (Ragin, 2008). However, given the consistency scores, the most relevant condition that was not necessary was "anxiety" in the Total Frequency dimension of the PIP, and family cohesion for the Total Difficulty score of the PIP.

\section{Sufficiency Analysis}

In the sufficiency analyses, taking into account that a model can be considered informative in SSQCA when its consistency is around 0.74 (Eng \& Woodside, 2012), the resulting models for the PIP dimensions were as follows:

In the prediction of the Total Frequency (Table 3): in the prediction of high levels of stress relative to the frequency of

Table 1 Main descriptions and calibration values 
Table 2 Necessity analysis for the PIP Total Frequency and PIP Total Difficulty scales

\begin{tabular}{|c|c|c|c|c|c|c|c|c|c|}
\hline & \multicolumn{2}{|c|}{$\begin{array}{l}\text { PIP Total } \\
\text { Frequency }\end{array}$} & \multicolumn{2}{|c|}{$\begin{array}{l}\sim \text { PIP Total } \\
\text { Frequency }\end{array}$} & & \multicolumn{2}{|c|}{$\begin{array}{l}\text { PIP Total } \\
\text { Difficulty }\end{array}$} & \multicolumn{2}{|c|}{$\begin{array}{l}\sim \text { PIP Total } \\
\text { Difficulty }\end{array}$} \\
\hline & Cons & $\mathrm{Cov}$ & Cons & Cov & & Cons & $\mathrm{Cov}$ & Cons & Cov \\
\hline Young & 0.73 & 0.56 & 0.56 & 0.67 & Young & 0.67 & 0.58 & 0.58 & 0.63 \\
\hline Young & 0.58 & 0.46 & 0.63 & 0.78 & 〜Young & 0.58 & 0.53 & 0.62 & 0.70 \\
\hline Anxiety & 0.75 & 0.65 & 0.51 & 0.69 & Anxiety & 0.69 & 0.68 & 0.49 & 0.61 \\
\hline$\sim$ Anxiety & 0.64 & 0.46 & 0.74 & 0.82 & $\sim$ Anxiety & 0.61 & 0.49 & 0.74 & 0.75 \\
\hline Depression & 0.72 & 0.66 & 0.46 & 0.66 & Depression & 0.62 & 0.65 & 0.49 & 0.61 \\
\hline$\sim$ Depression & 0.63 & 0.43 & 0.76 & 0.81 & $\sim$ Depression & 0.63 & 0.49 & 0.73 & 0.70 \\
\hline LSE & 0.67 & 0.67 & 0.37 & 0.57 & LSE & 0.62 & 0.70 & 0.36 & 0.50 \\
\hline$\sim \mathrm{LSE}$ & 0.56 & 0.36 & 0.78 & 0.79 & $\sim \mathrm{LSE}$ & 0.56 & 0.41 & 0.78 & 0.72 \\
\hline ESS & 0.47 & 0.50 & 0.41 & 0.68 & HR & 0.58 & 0.65 & 0.43 & 0.60 \\
\hline$\sim \mathrm{ESS}$ & 0.70 & 0.43 & 0.69 & 0.67 & $\sim \mathrm{HR}$ & 0.64 & 0.47 & 0.74 & 0.68 \\
\hline Cohesion & 0.69 & 0.37 & 0.73 & 0.62 & $\mathrm{EF}$ & 0.62 & 0.49 & 0.66 & 0.65 \\
\hline \multirow[t]{3}{*}{$\sim$ Cohesion } & 0.30 & 0.42 & 0.26 & 0.57 & $\sim \mathrm{EF}$ & 0.49 & 0.61 & 0.49 & 0.61 \\
\hline & & & & & Cohesion & 0.72 & 0.44 & 0.71 & 0.55 \\
\hline & & & & & $\sim$ Cohesion & 0.27 & 0.44 & 0.28 & 0.55 \\
\hline
\end{tabular}

Note. : absence of condition; LSE: "low self-esteem, need for approval and fear of rejection" scale; ESS: "emotional self-sufficiency and discomfort with intimacy" scale; HR: "hostile resolution of conflicts, resentment and possessiveness" scale; EF: "expression of feelings and comfort with relationships" scale; Cons: consistency; cov: coverage

Table 3 Summary of the main sufficient conditions for the intermediate solution of PIP Total Frequency and PIP Total Difficulty scales

\begin{tabular}{|c|c|c|c|c|c|c|c|c|c|c|c|c|}
\hline \multirow[t]{4}{*}{ Frequency cutoff: 1} & \multicolumn{6}{|c|}{ Frequency } & \multicolumn{6}{|l|}{ Difficulty } \\
\hline & \multicolumn{3}{|c|}{ PIP Total Frequency } & \multicolumn{3}{|c|}{$\sim$ PIP Total Frequency } & & \multicolumn{2}{|c|}{ PIP Total Difficulty } & \multicolumn{3}{|c|}{ PIP Total Difficulty } \\
\hline & \multicolumn{3}{|c|}{ Consistency cutoff: 0.82} & \multicolumn{3}{|c|}{ Consistency cutoff: 0.81} & & \multicolumn{2}{|c|}{ Consistency cutoff: 0.81} & \multicolumn{3}{|c|}{ Consistency cutoff: .89} \\
\hline & 1 & 2 & 3 & 1 & 2 & 3 & & 1 & 2 & 1 & 2 & 3 \\
\hline Young & $\bullet$ & $\circ$ & & & & $\bullet$ & Young & $\bullet$ & $\bullet$ & & $\circ$ & $\bullet$ \\
\hline Anxiety & $\bullet$ & $\bullet$ & & $\circ$ & & & Anxiety & $\bullet$ & $\bullet$ & ० & & ० \\
\hline Depression & $\bullet$ & $\bullet$ & $\bullet$ & $\circ$ & $\circ$ & ० & Depression & & $\bullet$ & ○ & $\circ$ & $\circ$ \\
\hline LSE & $\bullet$ & & $\bullet$ & & $\circ$ & ० & LSE & $\bullet$ & $\bullet$ & $\circ$ & & $\circ$ \\
\hline ESS & $\bullet$ & & $\bullet$ & & $\circ$ & & HR & $\bullet$ & & & ० & \\
\hline \multirow[t]{2}{*}{ Cohesion } & & $\circ$ & $\circ$ & $\bullet$ & $\bullet$ & $\bullet$ & $\mathrm{EF}$ & $\circ$ & ○ & & & \\
\hline & & & & & & & Cohesion & & & $\bullet$ & $\bullet$ & $\bullet$ \\
\hline Raw coverage & 0.30 & 0.15 & 0.13 & 0.49 & 0.40 & 0.33 & & 0.26 & 0.25 & 0.44 & 0.32 & 0.32 \\
\hline Unique coverage & 0.20 & 0.03 & 0.20 & 0.04 & 0.01 & 0.00 & & 0.03 & 0.02 & 0.02 & 0.02 & 0.00 \\
\hline Consistency & 0.85 & 0.83 & 0.85 & 0.85 & 0.88 & 0.95 & & 0.87 & 0.86 & 0.81 & 0.83 & 0.84 \\
\hline Overall solution consistency & & & 0.83 & & & 0.83 & & & 0.88 & & & 0.78 \\
\hline Overall solution coverage & & & 0.41 & & & 0.76 & & & 0.29 & & & 0.59 \\
\hline
\end{tabular}

Note. LSE: "low self-esteem, need for approval and fear of rejection" scale; ESS: "emotional self-sufficiency and discomfort with intimacy" scale; All sufficient conditions are adequate, raw coverage between 0.13 and $0.49 ; \sim=$ absence of condition (low levels) $\bullet=$ presence of condition, $\circ=$ absence of condition; HR: "hostile resolution of conflicts, resentment and possessiveness" scale; EF: "expression of feelings and comfort with relationships" scale Expected vector for PIP Total Frequency: -, 1, 1, 1, 1, 0 (0: absence; 1: attendance; -: neither presence nor absence)

Expected vector for PIP Total $\sim$ Frequency: -, 0, 0, 0, 0, 1

Expected vector for PIP Total Difficulty: -, 1, 1, 1, 1, 0

Expected vector for PIP Total $\sim$ Difficulty: -, 0, 0, 0, 0, 1 
situations arising from care, 4 pathways were observed that explained $41 \%$ of cases with high levels of stress (overall consistency $=0.83$; overall coverage $=0.41$ ). The most relevant pathway or combination for predicting stress relative to the frequency of situations arising from care was the interaction of being young, having high levels of anxiety and depression, having high scores on the "low self-esteem, need for approval and fear of rejection" insecure attachment subscale, and high scores on the "emotional self-sufficiency and discomfort with intimacy" adult attachment subscale (raw coverage $=0.30$; explaining $30 \%$ of cases with high stress). Meanwhile, in the prediction of low levels of stress relative to the frequency of care situations, 7 paths were observed that explained $76 \%$ of the cases with low levels of stress (overall consistency $=0.83$; overall coverage $=0.76$ ). The most relevant form or combination for predicting low levels of stress in the main family caregivers was low levels of anxiety, depression and having balanced cohesive family ties (raw coverage $=0.49$; explaining $49 \%$ of cases with low stress).

The prediction of Total Difficulty (Table 3): in the prediction of high stress levels related to the effort involved in situations arising from care, 2 pathways were observed that explained $29 \%$ of cases with high levels of stress (overall consistency $=0.88$; overall coverage $=0.29$ ). The most relevant pathway or combination for predicting stress related to the effort involved in situations arising from care was the interaction between being young, having high levels of anxiety and having high scores on the "low self-esteem, need for approval and fear of rejection" and "hostile resolution of conflicts, resentment and possessiveness" insecure attachment scales, and finally, low scores on the "expression of feelings and comfort with relationships" secure attachment scale (raw coverage = 0.29; explaining $29 \%$ of cases with high stress). Meanwhile, in the prediction of low levels of stress relative to the effort involved in care situations, 7 paths were observed that explained $59 \%$ of the cases with low levels of stress (overall consistency $=0.78$; overall coverage $=0.59$ ). The most relevant form or combination for predicting low levels of stress in the main family caregiver was the interaction between low levels of anxiety, depression, a low score on the "low selfesteem, need for approval and fear of rejection" insecure attachment scale and having balanced cohesive family ties (raw coverage $=0.49$; explaining $49 \%$ of cases with low stress).

\section{Discussion}

In addition to the changes that occur within the family due to the arrival of adolescence (Papalia et al., 2013), a child's diagnosis with a health problem can make the situation overwhelming (Valero-Moreno et al., 2018). SS, a diagnosis that occurs when the patient's height is below $-2 \mathrm{SD}$ for their age and sex in comparison to the reference population (Ying-Ju et al., 2020), is one of the most frequent diagnoses in pediatric endocrinology (Sevilla et al., 2015). SS in a child can affect the physical health and emotional well-being of caregivers (Quitmann et al., 2016), and their psychological condition is one of the most important factors in assessing the level of adjustment and adaptation of parents to their child's diagnosis (Johnson, 2013).

Taking into account that unadaptive reactions to the diagnosis by parents negatively influence the pediatric patient (Preston et al., 2016; Casaña-Granell et al., 2018; ValeroMoreno et al., 2018), our objective was to determine which factors influence the main family caregiver's adaptation to the pediatric patient's SS diagnosis, using models based on comparative qualitative analysis (QCA), given their advantages over other methods. To our knowledge, no previous studies have addressed the adjustment of primary caregivers of adolescents with SS, taking into account psychological and family variables, and using QCA models.

The literature has pointed out the presence of stress in primary caregivers as one of the most important factors in assessing their psychological adjustment (Johnson, 2013). In our study, the most important factors in predicting stress developed by primary family caregivers were: a) being young, presenting high levels of anxiety and depression, as well as high levels of insecure attachment (i.e. low self-esteem, need for approval and fear of rejection in the caregiver, and the presence of emotional self-sufficiency and discomfort with intimacy) and low family cohesion (for predicting the total stress scores for "frequency"); and b) being young, presenting high levels of anxiety, presenting high scores for insecure attachment (i.e. low self-esteem, need for approval and fear of rejection in the caregiver, and a tendency to hostile resolution of conflicts, resentment and possessiveness), and presenting low levels of secure attachment or a limited ability to express feelings and be comfortable with relationships" (for predicting total stress scores for "difficulty") and low family cohesion. The age of the caregiver, anxiety, attachment and family cohesion variables are therefore particularly important for predicting stress, and the "low self-esteem, need for approval and fear of rejection" insecure attachment indicator is particularly relevant.

During the care of the pediatric patient and above all, if the patient is in the middle of adolescence (with the conflicts and tensions in the family environment that this entails), situations may frequently arise that need to be managed both within the family and at the level of the healthcare team. The caregiver's type of attachment pattern when relating to his/her environment and handling situations is particularly important for this reason. If the caregiver has an insecure attachment pattern, his or her way of solving the problems will be less adaptive, and this will obviously create and reinforce higher levels of stress when providing care. Passive-aggressive behavior arising from anxiety about relationships and hostile conflict 
resolution, as well as a failure to seek support as a result of emotional self-sufficiency can lead to the resolution of each problem becoming a serious stress problem for the caregiver, which seriously hampers their ability to cope with situations.

If insecure attachment indicators lead to poor problem solving, these problems will often be perceived as a threat. This helps us understand why caregiver anxiety is the most important emotional factor in the caregiver's stress model, as it is constantly reinforced by the situations that accompany them. It is also possible that if they are young, the main family caregiver may lack the experience and maturity to deal with certain situations that they have to face, both within the family and in terms of the patient's medical treatment or follow-up. This possible insecurity about their own ability to manage the patient's care is related to higher levels of diagnostic stress (Tluczek, McKechnie, \& Brown, 2011).

As the literature emphasizes, a person's reactions will depend on various factors, such as their experience in crisis situations and their degree of vulnerability (Hernández \& Romero, 2010). In addition, emotional distress (both anxiety and depression) is a very important aspect when explaining and predicting the burden that the main family caregiver may develop (Valero-Moreno et al., 2018). The role of family cohesion is also important, as families with low levels of cohesion present more stress and those with higher levels of cohesion show less stress. Our data show that the ability to stay together as a family in the face of adversity is a protective factor against stress among caregivers of adolescents with SS.

Some limitations of the study should be taken into account when generalizing the results of this research. It is important to emphasize that the results presented above do not allow us to obtain any causal relationships between the variables of interest. The design used in this study only allows us to conclude that significant relationships exist between the variables, and as such future studies are required in greater depth, which clarify the results obtained with more precision, and evaluate the reliability of our data over time. It should be borne in mind that the number of primary family carers is not very large, and this is common in this type of study due to the difficulties involved in the sample collection process. However, the prediction method used (fsQCA) enables a small sample of case studies to be analyzed rigorously (Valero-Moreno, CastilloCorullón, Montoya-Castilla, \& Pérez-Marín, 2020). In future studies, it would also be interesting to have different methods of obtaining information to evaluate the variables studied, which could reduce the errors commonly made in self-reports.

In future lines of research, one of the objectives will be to increase the number of participants in the study, especially among the number of male caregivers, and to include participants from other hospitals in Spain and in other Spanishspeaking countries, in order to compare the samples. However, our data reflect the reality of care, in which the primary caregiver is usually female. In the case of adolescents, it is often the mother (Casaña-Granell et al., 2018). It would also be interesting to compare data from primary family caregivers of pediatric SS patients in this study with data from other pediatric populations, and from caregivers of younger SS patients.

Our results help to understand the emotional impact on primary caregivers of adolescents with SS, and with it, the factors that contribute to their mental health. We therefore observe how younger carers, who present additional emotional symptoms, present characteristics of insecure attachment and poor family cohesion, experience situations of greater stress which have more of an impact on their lives. These data mean that special attention must be paid to the family relationship and dynamics when caring for an adolescent with a chronic illness.

For all the above reasons, we believe that it would be beneficial for the healthcare system to consider primary family caregivers as objects of care, endeavoring to understand their concerns and beliefs regarding the problem affecting their children, as well as the psychosocial functioning of caregivers who clearly present poor adjustment to the diagnosis of the pediatric patient, so that an intervention that favors their quality of life can be developed and defined (Quitmann et al., 2016) and healthy strategies for coping with this type of difficulty can be developed (Quitmann et al., 2015).

In conclusion, we would like to point out that the presence of a greater number of stressful situations, as well as a greater emotional impact of these situations in caregivers of adolescents with SS, is associated with the combination of being young, presenting emotional symptoms (anxiety or depression), insecure attachment and low family cohesion. Family variables and affective bonds are especially important in the psychological adjustment of the primary caregivers of SS adolescents, so psychological interventions should address the family dynamics and emotional attachments of the members of the system.

Funding (Information that Explains whether and by Whom the Research Was Supported) Laura Lacomba-Trejo is a beneficiary of the "Talent Attraction" pre-doctoral research staff training grant from the University of Valencia (0113/2018).

Authors' Contributions (Optional: Please Review the Submission Guidelines from the Journal whether Statements Are Mandatory) All authors contributed to the study conception and design. Material preparation, data collection and analysis were performed by Sara Casaña-Granell, Laura Lacomba-Trejo, Inmaculada Montoya-Castilla and Marián Pérez-Marín. The first draft of the manuscript was written by Sara Casaña-Granell and all authors commented on previous versions of the manuscript. All authors have read and approved the final manuscript. 
Data Availability The datasets generated and/or analyzed during the current study are available from the corresponding author on reasonable request.

\section{Compliance with Ethical Standards}

Conflicts of Interest/Competing Interests (Include Appropriate Disclousures) The autors declare that they have no conflict of interest.

Ethics Approval (Include Appropriate Approvals or Waivers) This study was performed in line with the principles of the Declaration of Helsinki. Approval was granted by the Ethics Committee of University of Valencia Review Board (IRB) (Date. 02-03-2015/No. H141815452530).

Consent to participate (include appropriate statements) The participants signed the informed consent form before participating.

Consent for Publication (Include Appropriate Statements) The participants signed the informed consent form before participating. They allowed the use of the data obtained for scientific purposes such as disclosure or publication, provided their anonymity was preserved. The data were properly safeguarded at all times.

Code Availability (Software Application or Custom Code) Not applicable.

\section{References}

Aizpurua, P. G., Mateo, M. A., Alonso, Á. A., Juaristi, S. I., Carvajal, B. G., García, S. R., Jaca, S. M. (2020) Effect of changing reference growth charts on the prevalence of short stature. Anales de Pediatria (English Edition), 92(1), 28-36.

Alavi, M., Latif, A. A., Ninggal, M. T., Mustaffa, M. S., Amini, M. (2020). Family Functioning and Attachment Among Young Adults in Western and Non-Western Societies. The Journal of Psychology, 1-21.https://doi.org/10.1080/00223980.2020.1754153

Balola, M., Cláudio, V., \& do Rosário Ramos, M. (2019). Relation between autobiographical memory, attachment and early maladaptive schemas. Revista Argentina De Clínica Psicológica, 28(1), 183189. https://doi.org/10.24205/03276716.2019.1103.

Berenguer-Pérez, M., Barreto-Martín, P., \& Pérez-Marín, M. (2018). Apego y superación de la pérdida de una persona significativa. Revista Argentina de Clínica Psicológica, 28(1), 62-71. https:// doi.org/10.24205/03276716.2017.1043.

Brennan, K. A., \& Shaver, P. R. (1995). Dimensions of adult attachment, affect regulation, and romantic relationship functioning. Journal of Personality and Social Psychology, 21, 267-283. https://doi.org/10. 1177/0146167295213008.

Cano, M.A., González, F., De la Rosa, M., Amaro, H., Vega, W.A., Sánchez, M., ....de Dios, M. (2020). Depressive symptoms and resilience among Hispanic emerging adults: Examining the moderating effects of mindfulness, distress tolerance, emotion regulation, family cohesion, and social support. Behavioral Medicine, 46(3-4), 245-257. https://doi.org/10.1080/08964289.2020.1712646.

Casaña-Granell, S., Lacomba-Trejo, L., Valero-Moreno, S., PradoGasco, V., Montoya-Castilla, I., \& Pérez-Marín, M. (2018). A brief version of the pediatric inventory for parents (PIP) in Spanish population: Stress of main family carers of chronic paediatric patients. PLoS One, 13(7), e0201390. https://doi.org/10.1371/journal.pone. 0201390.

Claude, R., Christopher, R. (2014). Acq [Computer Programme].
Del Rincón, C., Remor, E., \& Arranz, P. (2007). Preliminary psychometric study of the Spanish version of the paediatric inventory for parents (PIP). International Journal of Clinical and Health Psychology, $7(2), 435-445$.

Eng, S., \& Woodside, A. G. (2012). Configural analysis of the drinking man: Fuzzy-set qualitative comparative analyses. Addictive Behaviors, 37(4), 541-543. https://doi.org/10.1016/j.addbeh.2011. 11.034 .

Giménez-Espert, M. C., Valero-Moreno, S., \& Prado-Gascó, V. J. (2019). Evaluation of emotional skills in nursing using regression and QCA models: A transversal study. Nurse Education Today, 74, 31-37. https://doi.org/10.1016/j.nedt.2018.11.019.

González, J., \& González, M. P. (2011). Niños con talla baja idiopática y tratamiento con hormona de crecimiento: situación actual. Evidencias en Pediatría, 7(55), 1-4.

Hernández, Z. E., \& Romero, E. (2010). Estrés en personas mayores y estudiantes universitarios: Un estudio comparativo. Psicología Iberoamericana, 18(1), 56-68.

Johnson, L. N. (2013). Parent Distress in Life with a Child with Type 1 Diabetes. (doctoral disertation). Florida: University of South Florida.

Kimelman, J. (2019). Apego normal, apego patológico y psicosis. Revista Chilena de Neuro-Psiquiatría, 57(1), 43-51. https://doi.org/10. 4067/S0717-92272019000100043.

Lei, X., \& Kantor, J. (2020). Study on family cohesion and adaptability of caregivers of children with ASD and its influencing factors. Social Psychology and Society, 11(3), 70-85.

Melero, R., \& Cantero, M. J. (2008). Cuestionario de apego adulto: evaluación en población española. Infocop, 40, 51-52 http://www. cop.es/infocop/pdf/1645. Accessed 20 March 2020.

Mikulincer, M., \& Shaver, P. R. (2012). An attachment perspective on psychopathology. World Psychiatry, 11, 11-15. https://doi.org/10. 1016/j.wpsyc.2012.01.003.

Mikulincer, M., \& Shaver, P. R. (2018). Attachment orientations and emotion regulation. Current Opinion in Psychology, 25, 6-10. https://doi.org/10.1016/j.copsyc.2018.02.006.

Monaghan, M., Horn, I. B., Alvarez, V., Cogen, F. R., \& Streisand, R. (2012). Authoritative parenting, parenting stress, and self-care in pre-adolescents with type 1 diabetes. Journal of Clinical Psychology in Medical Settings, 19(3), 255-261. https://doi.org/ 10.1007/s10880-011-9284-x.

Morán, J., \& Martínez, C. (2019). El apego en la adolescencia: una revisión sistemática de la investigación latinoamericana durante los últimos 15 años. Revista Argentina de Clínica Psicológica, 28(2), 172-182. https://doi.org/10.24205/03276716.2019.1098.

Nicholls, W., Hulbert-Williams, N., Bramwell, R. (2014) The role of relationship attachment in psychological adjustment to cancer in patients and caregivers: a systematic review of the literature. Psycho-Oncology, 23(10), 1083-1095.

Olson, D. H., Russell, C. S., \& Sprenkle, D. H. (1983). Circumplex model of marital and family system, VI: Theoretical update. Family Process, 22, 69-83. https://doi.org/10.1111/j.1545-5300.1983. 00069.x.

Olson, D.H., Portner, J. y Lavee, Y. (1985). Manual de la Escala de Cohesión y Adaptabilidad Familiar (FACES III Manual). Minneapolis: Life Innovation.

Orkaizagirre-Gómara, A., Sánchez, M., Ortiz, J., \& Ortiz, A. (2020). Testing general self-efficacy, perceived competence, resilience, and stress among nursing students: An integrator evaluation. Nursign \& Health Sciences, 22(3), 229-538. https://doi.org/10. 1111 /nhs. 12689.

Pampliega, A. M., Castillo, I. I., Sanz, M., \& Galíndez, E. (2006). Family Adaptability and Cohesion Evaluation Scale (FACES): desarrollo de una versión de 20 ítems en español. International Journal of Clinical and Health Psychology, 6(2), 317-338. 
Papalia, D., Wendkos, S., \& Duskin, R. (2013). Desarrollo Humano. México: McGraw-Hill.

Pombo, M., Castro-Feijóo, L., \& Cabanas, P. (2011). El niño de talla baja. Protocolos diagnósticos y terapéuticos en pediatría, 1, 236-254.

Preston, A., Storch, E., A. Lewin, A., Geffken, G., R. Baumeister, A., L. Strawser, M., S. Silverstein, J. H. (2016) Parental stress and maladjustment in children with short stature. Clinical Pediatrics, 44(4), 327-331.

Quintana, J. M., Padierna, A., Esteban, C., Arostegui, I., Bilbao, A., \& Ruiz, I. (2003). Evaluation of the psychometric characteristics of the Spanish version of the hospital anxiety and depression scale. Acta Psychiatrica Scandinava, 107(3), 216-221. https://doi.org/10.1034/ j.1600-0447.2003.00062.x.

Quitmann, J., Rohenkohl, A., Specht, A., Petersen-Ewert, C., Schillmöller, Z., \& Bullinguer, M. (2015). Coping strategies of children and adolescents with clinically diagnosed short stature. Journal of Child and Family Studies, 24, 703-714. https://doi.org/10.1007/ s10826-013-9880-5.

Quitmann, J. H., Bullinger, M., Sommer, R., Rohenkohl, A. C., \& Da Silva, N. M. B. (2016). Associations between psychological problems and quality of life in pediatric short stature from patients' and parents' perspectives. PLoS One, 11(4), e0153953. https://doi.org/ 10.1371/journal.pone.0153953.

Quitmann, J., Bloemeke, J., Silva, N., Bullinger, M., Witt, S., Akkurt, I., Dunstheimer, D., Vogel, C., Böttcher, V., Kuhnle Krahl, U., Bettendorf, M., Schönau, E., Fricke-Otto, S., Keller, A., Mohnike, K., \& Dörr, H.-G. (2019). Quality of life of short-statured children born small for gestational age or idiopathic growth hormone deficiency within 1 year of growth hormone treatment. Frontiers in Pediatric., 7(164). https://doi.org/10.3389/fped.2019.00164.

Ragin, C. C. (2008). Redesingning social inquiry: Fuzzy sets and beyond. Chicago: University of Chicago Press.

Sicouri, G., Sharpe, L., Hudson, J. L., Dudeney, J., Jaffe, A., Selvadurai, H., Lorimer, S., \& Hunt, C. (2017). Threat interpretation and parental influences for children with asthma and anxiety. Behaviour Research and Therapy, 89, 14-23. https://doi.org/10.1016/j.brat. 2016.11.004.

Silva, N., Bullinger, M., Sommer, R., Rohenkohl, A., Witt, S., \& Quitmann, J. (2018). Children's psychosocial functioning and parents' quality of life in paediatric short stature: The mediating role of caregiving stress. Clinical Psychology y Psychotherapy, 25(1), e107-e118.

Streisand, R., Braniecki, S., Tercyak, K. P., \& Kazak, A. E. (2001). Chilhood illness-related parenting stress: The pediatric inventory for parents. Journal Pediatric Psychology, 26, 155-162. https:// doi.org/10.1093/jpepsy/26.3.155.

Tluczek, A., McKechnie, A. C., \& Brown, R. L. (2011). Factors associated with parental perception of child vulnerability 12 months after abnormal newborn screening results. Research in Nursing \& Health, 34, 389-400. https://doi.org/10.1002/nur.20452.

Tsibidaki, A. (2020). Family functioning and strengths in families raising a child with cerebral palsy. Research in Developmental Disabilities, 106, 103767.
Valero-Moreno, S., Pérez-Marín, M., Montoya-Castilla, I., CastilloCorullon, S., Ramírez-Aguilar, A., \& Escribano-Montaner, A. (2018). Emotional distress in family caregivers of adolescents with bronchial asthma: Analysis of its predictors. Archivos argentinos de pediatria, 116(2), e234-e240.

Valero-Moreno, S., Lacomba-Trejo, L., Casaña-Granell, S., PradoGascó, V., Montoya-Castilla, I., \& Pérez-Marín, M. (2019). Factor structure of the hospital anxiety and depression scale in adolescent patients with chronic disease. Archivos Argentinos de Pediatría, 117(4), 252-258. https://doi.org/10.5546/aap.2019.eng.252.

Valero-Moreno, S., Castillo-Corullón, S., Montoya-Castilla, I., \& PérezMarín, M. (2020). Primary ciliary dyskinesia and psychological well-being in adolescence. PLoS One, 15(1), e0227888. https:// doi.org/10.1371/journal.pone.0227888.

Vrijmoet-Wiersma, C. J., Ottenkamp, J., van Roozendaal, M., Grootenhuis, M. A., \& Koopman, H. M. (2009). A multicentric study of disease-related stress, and perceived vulnerability, in parents of children with congenital cardiac disease. Cardiology in the Young, 19(06), 608-614. https://doi.org/10.1002/pon.1571.

Wang, A., Bai, X., Lou, T., Pang, J., \& Tang, S. (2020). Mitigating distress and promoting positive aspects of caring in caregivers of children and adolescents with schizophrenia: Mediation effects of resilience, hope, and social support. International Journal of Mental Health Nursing, 29(1), 80-91. https://doi.org/10.1111/inm.12651.

Wu, D., Chen, R. M., Chen, S. K., Liu, G. L., Chen, L. Q., Yang, Y., Wang, X. L., Peng, Y. G., \& Gong, C. X. (2020). Final adult height of children with idiopathic short stature: A multicenter study on GH therapy alone started during peri-puberty. BMC Pediatrics, 20, 1-7. https://doi.org/10.1186/s12887-020-02034-8.

Xiaoyun, C., \& Fenglan, L. (2020). The relationships among insecure attachment, social support and psychological experiences in family caregivers of cancer inpatients. European Journal of Oncology Nursing, 44, 101691. https://doi.org/10.1016/j.ejon.2019.101691.

Ying-Ju, L., Chi-Fung, C., Chung-Hsing, W., Wen-Miin, L., Chih-Hsin, T., \& Li-Ping, T. ... Fuu-Jen, T. (2020). Genetic architecture associated with familial short stature. The Journal of Clinical Endocrinology \& Metabolims, 105(6), dgaa131. https://doi.org/10. 1210/clinem/dgaa131.

Zayed, A. A., Beano, A. M., Haddadin, F. I., Radwan, S. S., Allauzy, S. A., \& Alkhayyat, M.M ... Yousef, A.F. (2016). Prevalence of short stature, underweight, overweight, and obesity among school children in Jordan. BMC Public Health, 16, 1040. https://doi.org/10. 1186/s12889-016-3687-4

Zigmond, A. S., \& Snaith, R. P. (1983). The hospital anxiety and Depression scale. Acta Psychiatrica Scandinavica, 67, 361-370. https://doi.org/10.1111/j.16000447.1983.SS09716.x.

Publisher's Note Springer Nature remains neutral with regard to jurisdictional claims in published maps and institutional affiliations. 